\title{
A study on the behavior of pile supported footings on sand
}

\author{
V. Balakumar, Min Huang, Erwin Oh and A.S. Balasubramaniam \\ ${ }^{I}$ Simplex Infrastructures Limited, Chennai, Tamil Nadu, India.vb_kumar2002@yahoo.com \\ ${ }^{2}$ Arup Geotechnics, Australia.m.huang@outlook.com \\ ${ }^{3}$ Griffith School of Engineering, Griffith University, Australia.y.oh@griffith.edu.au \\ ${ }^{4}$ Griffith School of Engineering, Griffith University, Australia. a.bala@griffith.edu.au
}

\begin{abstract}
When the bearing capacity is not adequate to provide isolated footings, columns are grouped and supported combined footing. However if the settlement increases beyond the permissible limits, piles are provided below the combined footing, applying the concept of piled raft. In this case the piles function as settlement reducers. Such systems can be categorized as a particular case of the combined piled raft system. In the present study a typical case of a piled raft with relatively smaller width, supported on two rows of piles on the edges was studied with small scale $1 \mathrm{~g}$ model tests for understanding the basic behavior and a numerical study to obtain the details of raft settlement and the shaft stress distribution along the pile length.
\end{abstract}

Key words: Model test, settlement, plane strain, piled raft

\section{INTRODUCTION}

Among the various types of structures, industrial structures are provided with row of columns to support large span roof structure. Such columns are provided with isolated footings or combined footings, depending upon the column load and the available allowable bearing pressure. But when the settlement exceeds the permissible value, such combined footings can be supported on piles, adopting the concept of combined piled raft foundation. In this particular case also, the piles provided below the combined footings act as settlement reducers. Such a foundation system can be considered as a particular case of piled raft.

\section{HISTORY}

After Burland (1995) brought out in detail, the use of piles below the raft to reduce the settlement of the raft, large volume of work have been done in the last two decades to understand the behavior and performance of piled raft through various approaches (Poulos 2001; Nguyen etal.,2016; ,(Balakumar,2008;Elwakil and Azzum2016) inclusive of monitoring the real time piled raft (Katzenbach etal.,2000a; Poulos2008, Balakumar and Ilamparuthi 2007;Yamashita etal., 2010 )

Researchers like Butterfield and Bannerjee (1971) Hongladaromp etal.,(1973), Weisner and Brown (1975) had studied the behavior of pile supported footings by adopting boundary element method or finite difference method. Weisner and Brown (1975) studied the behaviour of strip raft subjected to concentrated load and uniformly distributed load. They showed that the piles took a higher load and there was a reduction in the displacement and settlement.

Poulos (1991) in his study on the analyses of piled strip footings using elastic theory, studied the effect of each constituent elements on the other, to arrive at the final solution under various loading conditions. Long (1993) conducted a detailed study on the behaviour of piled footings and showed that, in the initial stages the piles were taking more load than the caps resting on the ground. He had indicated that the installation sequence has no effect but the compaction mainly affects the shaft friction..

However Poulos (1991) had pointed out that, the methods adopted in all these studies were subject to a lot of limitations and involve substantial efforts to obtain a convincing solution. Weisner and. Brown (1975) had expressed that, due to the lack of adequate parameters required to specify this type of problem, the results presented cannot be treated as complete, but they may prove sufficient for design.

\section{OBJECTIVE AND METHODOLOGY}

The above limitations establish the need to understand the difference between the behaviour of piled raft, and pile supported combined footings, which are a particular case of piled raft, with only two rows of piles in the edges. As the first step, $1 \mathrm{~g}$ model tests were conducted on the piled raft under consideration, to study the general behaviour, The tests were conducted in a tank of $1000 \mathrm{~mm} \times 1000 \mathrm{~mm} \times 600 \mathrm{~mm}$. The model size was $70 \mathrm{mmx} 200 \mathrm{~mm}$; The L/B (The Length to Breadth ratio) ratio of the raft was kept more than 2 .

\section{DETAILS OF THE MODEL STUDY.}

Figure 1 provides the typical rectangular pile supported footing and square footing. The raft sizes were $200 \mathrm{~mm} \times 200 \mathrm{~mm}$ in the case of square raft and $70 \mathrm{~mm} \times 200 \mathrm{~mm}$ in the case of rectangular footing respectively. In either case the raft thickness was maintained as $8 \mathrm{~mm}$ and the pile diameter was kept was $10 \mathrm{~mm}$.Figure 2 provides the experimental set up used for conducting the model tests and also the details of pile raft connection. The loading plate which has very closely spaced studs transfers the applied load as UDL without any additional stiffness getting transferred due to the loading plate. The tests were conducted in a specially fabricated steel tank of size $1000 \mathrm{mmx} 1000 \mathrm{mmx} 600 \mathrm{~mm}$.

Clean Palar river sand was used in all the experiments as a test medium. Laboratory tests were conducted on the representative sand samples for gradation, specific gravity, maximum and minimum dry unit weights and angle of sharing resistance for different densities as per relevant ASTM standards

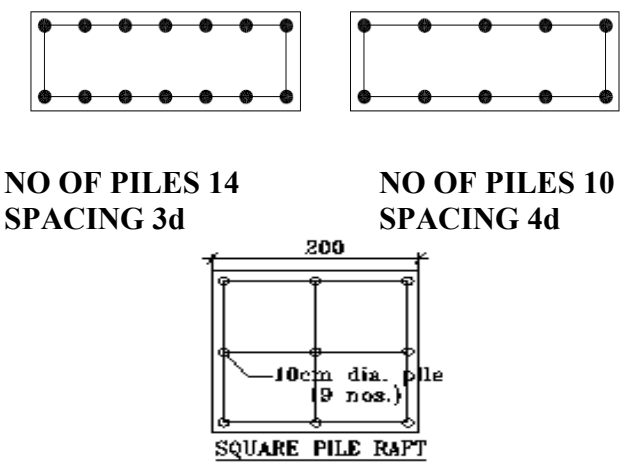

Figure 1 Layout of piled footings 
The index properties obtained are presented in Table 1 and the sand is classified as poorly graded sand (SP). The angle of shearing resistance obtained was used in the validation of analytical model for various densities and are also presented in Figure 3.

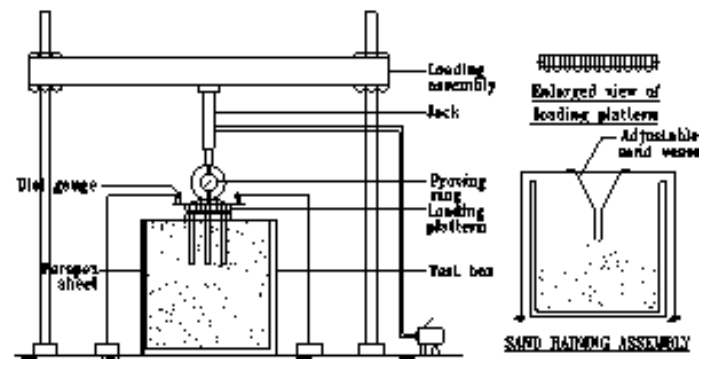

Figure 2: Test setup

In order to avoid the scale effect, the tank size $(1000 \mathrm{~mm} \times 1000 \mathrm{~mm})$ was such that the ratio of the tank size to model size $(200 \mathrm{~mm} \times 70 \mathrm{~mm})$ was kept as 5 .

Table 1 Material properties

\begin{tabular}{|l|c|c|}
\hline \multicolumn{1}{|c|}{ Parameter } & Symbol & Value \\
\hline Maximum dry unit weight & $\gamma_{\mathrm{dmax}}$ & $18.19 \mathrm{kN} / \mathrm{m}^{3}$ \\
\hline Minimum dry unit weight & $\gamma_{\mathrm{dmin}}$ & $14.41 \mathrm{kN} / \mathrm{m}^{3}$ \\
\hline Maximum void ratio & $\mathrm{e}_{\max }$ & 0.84 \\
\hline Minimum void ratio & $\mathrm{e}_{\min }$ & 0.46 \\
\hline Specific gravity & $\mathrm{G}$ & 2.65 \\
\hline Coarse sand & & $3 \%$ \\
\hline Medium sand & & $85 \%$ \\
\hline Fine sand & & $12 \%$ \\
\hline Effective grain size & $\mathrm{D}_{10}$ & 0.38 \\
\hline Uniformity coefficient & $\mathrm{Cu}_{\mathrm{u}}$ & 2.63 \\
\hline Coefficient of curvature & $\mathrm{Cc}$ & 1.22 \\
\hline Classification & $\mathrm{SP}-$ Uniformly graded sand \\
\hline
\end{tabular}

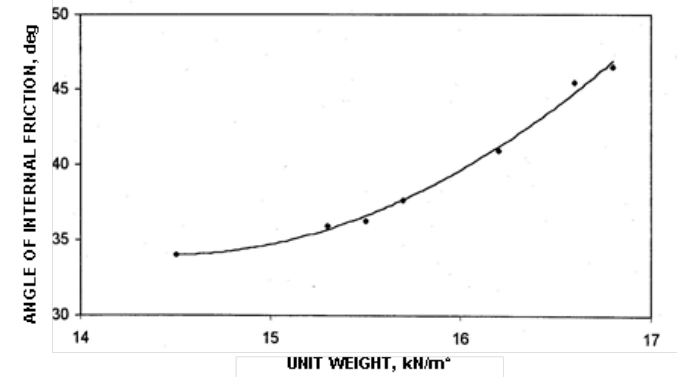

Figure 3 Variation of angle of internal friction with unit weight

Although extensive studies using circular and square piled rafts also have been carried out (Balakumar,2008), this presentation is restricted to the extent of tests carried out on piled footing with the footing resting on medium dense sand bed. A non dimensional plot was made for every series of tests and a typical plot is shown in Figure 4 , to eliminate the scale effect.

Since the behavior was identical in the case of circular and square raft, this was not repeated in the case of rectangular one. This plot confirmed that there was no scale effect. The study by $\mathrm{Oh}$ and Vanapalli(2003) also confirmed this. Moreover, the applied stress level $\left(0.13 \mathrm{n} / \mathrm{mm}^{2}\right)$ was restricted to a settlement level of $12 \mathrm{~mm}$. The bed material being poorly graded palar sand, it was expected that there would not be any crushing of grains (Bolton and Lau,1989).

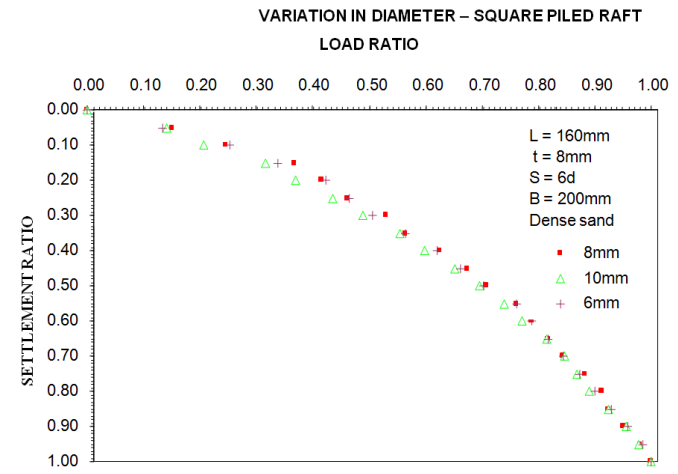

Figure 4 Non-dimensional plots for piled raft with different pile diameters

The tests were carried out by keeping the raft thickness as $8 \mathrm{~mm}$ and the bed density as medium dense.. Loads were applied in steps through a 2 te hydraulic jack fitted with a proving ring of the same capacity. The settlement was measured and recorded through a high precision dial gauges. The maximum settlement was found to be $12 \mathrm{~mm}$, and there after the piled raft did not take any further load.

\section{RESULT, ANALYSES AND DISCUSSIONS}

Results presented in this section are typically for a pile- footing (raft) area ratio of $3.75 \%$ ) In all the other cases studied the behaviour observed was similar. Figure 5 provides the load settlement response of unpiled footing $(200 \mathrm{~mm} \times 70 \mathrm{~mm} \times 8 \mathrm{~mm})$, piled footing $(10 \mathrm{~mm}$ dia piles $75 \mathrm{~mm}$ long, with $4 \mathrm{~d}$ spacing) and pile group of piled footing.

It can be seen from the load settlement curve that the pile group of piled footing loses its stiffness rapidly as the load applied on the piled footing increases.

LOAD, kN

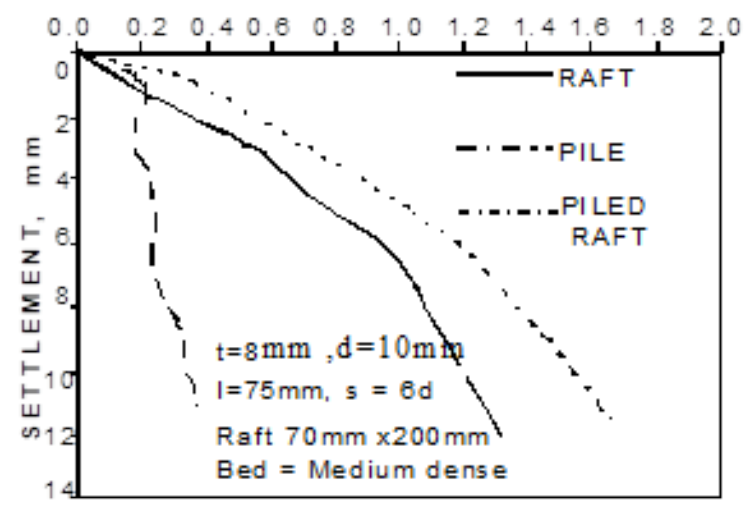

Figure 5 Load settlement response of piled footing, unpiled footing and pile group of piled footing

In the case of piled raft up to a settlement of nearly $0.7 \mathrm{~mm}$, which is $1 \%$ of the least lateral dimension of the footing, the rate of increase in the settlement is very small. The load corresponding to this settlement is equal to $0.20 \mathrm{kN}$ which is $18 \%$ of the load corresponding to a maximum settlement of $12 \mathrm{~mm}$ to which the test was conducted. Beyond $12 \mathrm{~mm}$ settlement, the piled footing did not take further load. At any given load it was seen that the piled footing settlement is far less than the plain footing settlement. Upto a settlement of $5 \mathrm{~mm}$, the rate of increase in the settlement is moderate, and beyond $5 \mathrm{~mm}$ settlement the rate of change in the settlement is rapid.

Figure 6 provides the characteristic load-settlement response of piled footing obtained by plotting the same load settlement curve in semi-log scale. It can be seen that the system exhibits three-phase behavior. The three phase behavior of the piled raft indicates that up to a settlement level of $1.2 \mathrm{~mm}$ (stage OA), the behavior is elastic and at 
this stage the pile group takes the maximum share (refer Figure 9) of the load applied on the piled footing.

Stage $\mathrm{AB}$ indicates that, as the loading increases, the rate of loss of stiffness increases. This stage extends up to a settlement level of $5 \mathrm{~mm}$ and beyond this settlement, it is seen that even for a small increase in the load, the piled raft settles down rapidly, indicating that the loss of stiffness is more rapid than in the case of stage AB.

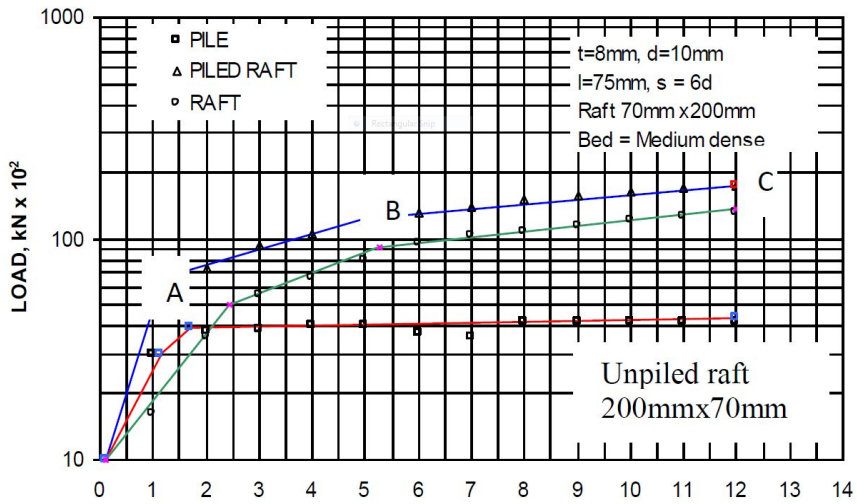

Figure 6 Characterized load settlement response of piled footing (raft as referred)

The second phase as shown by the line AB. The Table 2 provides the comparison of stiffness at various phases. It is seen that as the settlement increases, the stiffness reduces and approaches the stiffness of the un-piled footing.

The stiffness of un-piled and piled footing being numerically equal, in the stage $\mathrm{BC}$ is a strange coincidence, perhaps due to a small pile raft area ratio $(3.75 \%)$ and length of the pile which is $75 \mathrm{~mm}$, being more or less equal to raft width. However in all the other cases studied, at the stage BC the stiffness of the piled footing was higher than the unpiled footing by around $25 \%$ to $35 \%$. (Balakumar 2008)

However as matter of comparison,the stiffness variation in the case of a square footing $200 \mathrm{~mm} \times 200 \mathrm{~mm}$ size having nine piles (pile-raft area ratio $1.8 \%$, far less than the pile raft area ratio considered in the rectangular footing,) is shown in Table 3. It can be seen that the trend of variation remains same, but the percentage of reduction in the case of rectangular footing is far less with two rows of piles. It can also be seen that in spite of very low pile-raft area ratio in the case of square footing the pile disposition provides a much better confinement which generates a much higher stiffness even under failure settlement.

Table 2 Comparison of load and stiffness $(\mathrm{N} / \mathrm{mm})$ for Plain footing and piled footing $\left(\right.$ Size $=70 \mathrm{~mm} \times 200 \mathrm{~mm}, d=10 \mathrm{~mm}, \mathrm{~A}_{\mathrm{r}}=$ $3.75 \%, \mathrm{~N}=6, \mathrm{~L}=160 \mathrm{~mm}, \mathrm{t}=8 \mathrm{~mm}$ )

\begin{tabular}{|c|c|c|c|c|c|c|}
\hline \multirow[b]{2}{*}{ System } & \multicolumn{2}{|l|}{ OA } & \multicolumn{2}{|l|}{$\mathrm{AB}$} & \multicolumn{2}{|l|}{ BC } \\
\hline & $\begin{array}{l}\text { Load } \\
(\mathrm{kN})\end{array}$ & $\begin{array}{l}\text { Stiffness } \\
\mathrm{N} / \mathrm{mm}\end{array}$ & $\begin{array}{l}\text { Load( } \\
\mathrm{kN})\end{array}$ & $\begin{array}{l}\text { Stiffness } \\
\mathrm{N} / \mathrm{mm}\end{array}$ & $\begin{array}{l}\text { Load } \\
(\mathrm{kN})\end{array}$ & $\begin{array}{l}\text { Stiffnes } \\
\text { s } \\
\mathrm{N} / \mathrm{mm}\end{array}$ \\
\hline $\begin{array}{l}\text { Plain } \\
\text { foot. }\end{array}$ & 0.41 & 171 & 0.8 & 150 & 1.5 & 100 \\
\hline $\begin{array}{l}\text { Piled } \\
\text { foot. }\end{array}$ & 0.69 & 530 & 1.08 & 219 & 2.2 & 100 \\
\hline
\end{tabular}

From the comparison presented in Figure $7 \mathrm{a}$ and Figure $7 \mathrm{~b}$, it can be clearly seen that when the load acts in between the pile, the load sharing response is far better than the load sharing response under the uniformly distributed load condition, perhaps with a possible increase in the raft moment, which needs further study.

It is seen that the pile group takes higher load at any settlement level when the load acts as point load in between the piles than when the load is applied as UDL. However it is to be noted that the raft bending moment may increase
Table 3 Stiffness for square piled raft $-\mathrm{N}=9$, SIZE $200 \mathrm{X} 200 \mathrm{~L}=160$

$\mathrm{A}_{\mathrm{S}}=1.8 \% \mathrm{~T}=8 \mathrm{~mm}$

\begin{tabular}{|c|c|c|c|c|c|c|}
\hline \multirow{2}{*}{ System } & \multicolumn{2}{|c|}{ OA } & \multicolumn{2}{c|}{ AB } & \multicolumn{2}{c|}{ BC } \\
\cline { 2 - 7 } & Load & $\begin{array}{c}\text { Stiffness } \\
\text { N/mm }\end{array}$ & $\begin{array}{c}\text { Loa } \\
\mathbf{d}\end{array}$ & $\begin{array}{c}\text { Stiffness } \\
\text { N/mm }\end{array}$ & Load & $\begin{array}{c}\text { Stiffness } \\
\text { N/mm }\end{array}$ \\
\hline $\begin{array}{c}\text { PLAIN } \\
\text { RAFT }\end{array}$ & 1.40 & 720 & 2.20 & 366 & 5.60 & 280 \\
\hline $\begin{array}{c}\text { PILIED } \\
\text { RAFT }\end{array}$ & 1.88 & 940 & 3.55 & 592 & 7.40 & 390 \\
\hline
\end{tabular}

RECTANGULAR RAFT - 8MM RAFT - LOAD ON PILE

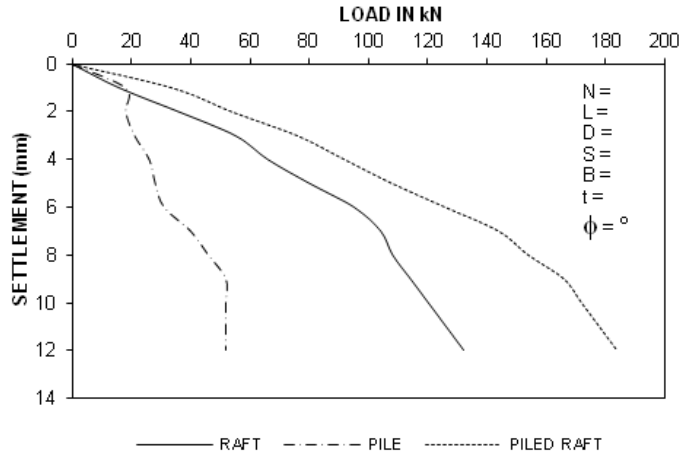

Figure 7a Load settlement response -Uniformly distributed loading (UDL) (:n - number of piles; b-width of the raft d diameter of the pile $\mathrm{s}$ is the spacing and $\mathrm{b}$ is the width of the raft).

\subsection{Settlement reduction and load sharing response.}

The performance of piled footing is understood by two parameters, namely settlement reduction ratio given by the expression,

$\mathrm{S}_{\mathrm{r}}=\left(\mathrm{S}_{\mathrm{R}}-\mathrm{S}_{\mathrm{PR}}\right) / \mathrm{S}_{\mathrm{R}}$

(Where $S_{r}$ is the settlement reduction ratio, $S_{R}$ is the settlement of un-piled raft, and SPR is the settlement of piled raft at the same load as considered for un-piled raft) and load sharing ratio given by

$\alpha_{\mathrm{pr}}=\left(\mathrm{PPR}-\mathrm{P}_{\mathrm{R}}\right) / \mathrm{P}_{\mathrm{R}}$

Where, $\alpha_{\mathrm{pr}}$ is the load sharing ratio, $\mathrm{P}_{\mathrm{PR}}$ and $\mathrm{P}_{\mathrm{R}}$ are the load taken by the piled raft and un-piled raft, at the same settlement level.

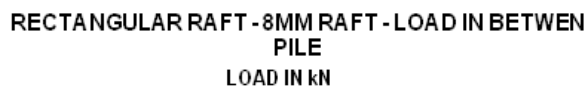

$\begin{array}{llllllllllllll}0 & 20 & 40 & 60 & 80 & 100 & 120 & 140 & 160 & 180 & 200 & 220 & 240 & 260\end{array}$

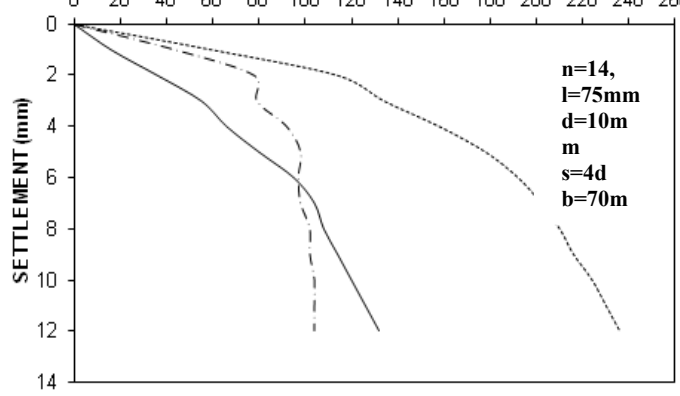

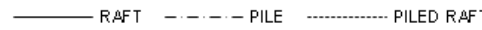

Figure 7b Load settlement response- Load in between piles as point load

Extensive parametric studies were conducted to understand the effect of pile length, pile diameter and spacing on the settlement reduction and load sharing behavior (Balakumar, 2008). Figure 8 
presents typically the variation trend of $S_{R}$ at $2 \mathrm{~mm}$ settlement level and $12 \mathrm{~mm}$ settlement level with the pile diameter.

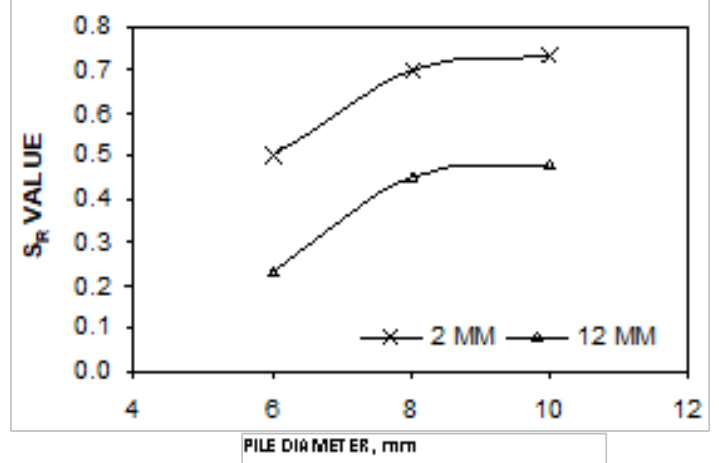

Figure 8 Variation of $S_{R}$ with pile dia

The load sharing response as in Figure 9, was found to be settlement dependent irrespective of the type of loading. For this study, the model with $4 \mathrm{~d}$ spacing of $10 \mathrm{~mm}$ dia piles, $75 \mathrm{~mm}$ long placed under $8 \mathrm{~mm}$ thick raft was used

The load sharing response indicates that beyond a settlement level of $6 \mathrm{~mm}(50 \%$ of the failure settlement) the load sharing ratio reduces and then remains more or less constant.

\subsection{Interaction behaviour}

The settlement reduction and the load sharing behaviour are the consequences of interaction among the constituting elements namely pile group, footing and the supporting soil. A detailed parametric study on the interaction behavior in the case of circular and square raft was studied earlier (Balakumar etal., 2013) with the same expression as used by Randolph (1983). A similar study was carried out in this case of piled footing also and the results are provided in the Table 4.

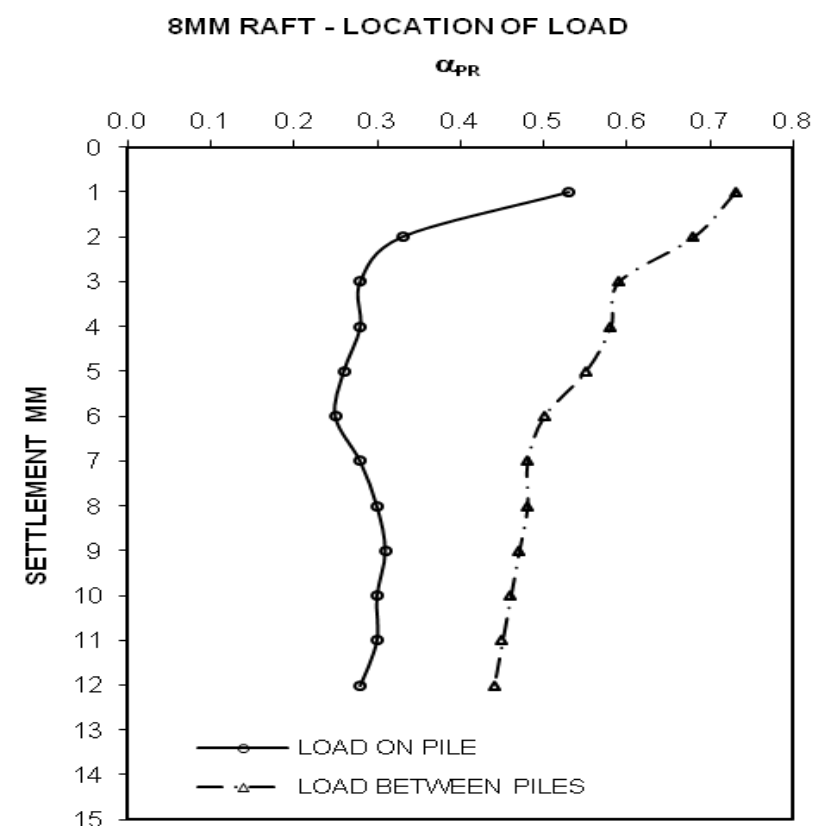

Figure 9 Load sharing response- comparisons

From the above table it is clearly seen that, in the case of piled footing, the interaction factor is far less than circular piled raft at all the area ratio levels as shown typically, at $50 \%$ of the failure settlement. The interaction behavior in such cases need further study.
Table 4 Comparison of Interaction factor at $50 \%$ of the failure Settlement at various pile- raft area ratios-(ratio of total cross sectional area of piles $A_{P}$ to footing plan area $\left.A_{R}\right)$ at $50 \%$ of failure settlement

\begin{tabular}{|c|c|c|c|c|}
\hline \multirow{2}{*}{ Piled raft } & \multicolumn{4}{|c|}{ Area Ratio- $\mathrm{AP} / \mathrm{AR}_{\mathrm{R}}$} \\
\cline { 2 - 5 } & $9 \%$ & $6 \%$ & $5.25 \%$ & $4 \%$ \\
\hline $\begin{array}{c}\text { Circular } \\
\text { piled raft }\end{array}$ & 0.89 & 0.57 & 0.45 & 0.37 \\
\hline $\begin{array}{c}\text { Piled } \\
\text { Footing }\end{array}$ & 0.56 & 0.39 & 0.26 & 0.17 \\
\hline
\end{tabular}

\subsection{Numerical analyses}

While the small scale model studies predicted the general behavior of this type of pile supported combined footing, the numerical modeling showed the settlement profile below the footing and shaft stress distribution over the length of the pile. The numerical study was done with plane strain analysis using FEA code Ansys. . The soil medium (details are in Table 1 and 5) below the raft was modelled using an eight-nodded brick element (SOLID 45), having three degrees of freedom of translations in the respective co-ordinate directions at each node. The soil was idealized as an isotropic homogenous half-space. The nonlinear behaviour of the soil was modeled using the multi-linear isotropic hardening (MISO) material model of ANSYS. This model incorporates the Von-Mises yield criterion, with associated flow rule and isotropic work hardening. The present analyses of the foundation system were restricted to only vertical loading. As stated by Potts and Zdrakovic (2000), although the load settlement behavior is dominated by the interface element stiffness,(,measuring the interface stiffness being difficult), instead of using higher stiffness values, it was suggested not to use interface elements, as this is acceptable when the analyses was done with only vertical loading. It was observed by Reul and Randolph (2002) mesh refinement does not have any appreciable effect the study was done with relatively coarser mesh.

Table 5 Details of piled footing and bed material $\mathrm{N}=$ number of piles (14) $t=$ thickness

\begin{tabular}{|c|c|c|c|c|c|c|c|}
\hline \multicolumn{2}{|l|}{ Raft } & \multicolumn{3}{|c|}{ Piles } & \multicolumn{3}{|c|}{ Sand bed } \\
\hline $\begin{array}{l}\text { Size } \\
B \times L\end{array}$ & $\begin{array}{l}\mathrm{t} \\
\mathrm{mm}\end{array}$ & $\mathrm{N}$ & $\begin{array}{l}\text { Length } \\
\mathrm{mm}\end{array}$ & $\begin{array}{l}\text { Area } \\
\text { ratio } \\
\%\end{array}$ & $\begin{array}{l}\text { Bed } \\
\text { density } \\
\mathrm{kN} / \mathrm{m}^{3}\end{array}$ & $\begin{array}{l}\mathrm{E}_{\mathrm{s}} \\
\mathrm{MPa}\end{array}$ & $v_{\mathrm{s}}$ \\
\hline $70 \times 200$ & 8 & 14 & 75 & 7.85 & 15.5 & 35 & 0.3 \\
\hline
\end{tabular}

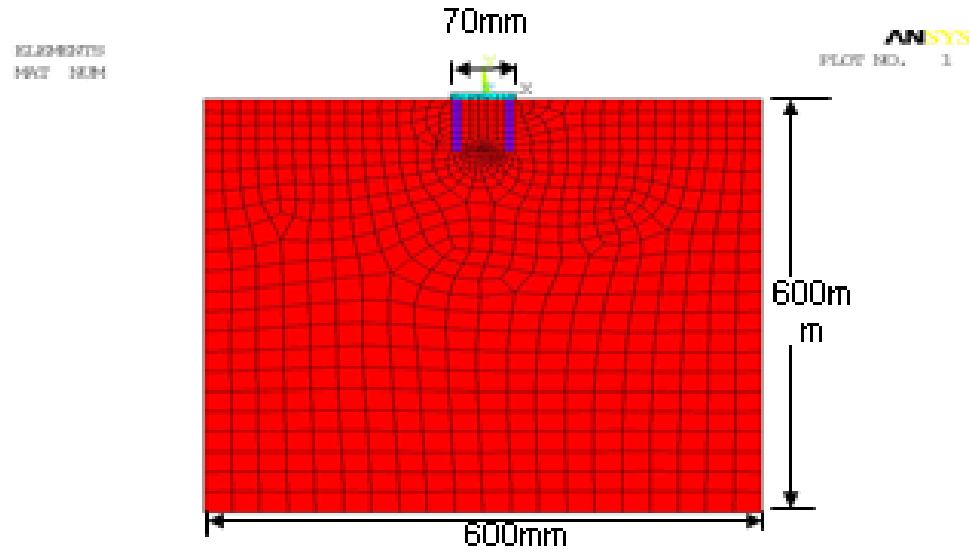

Figure 10 Plane strain model 


\subsection{RECTANGULAR FOOTING}

Figure 10 provides the finite element model and the mesh. The loading was applied as UDL in small increments, and the settlement was obtained for each load increments. Figure 11 presents load settlement response of plane strain analysis which compares well with the model test curve.

As shown in the Figure 11, the plane strain model predicts a stiffer response compared to the $1 \mathrm{~g}$ model test.

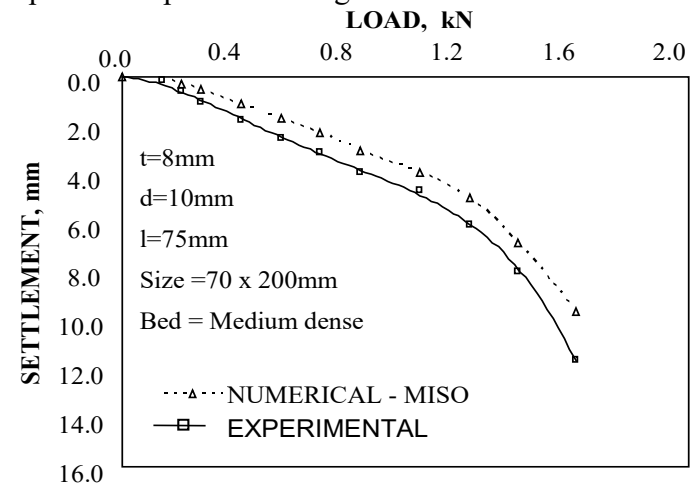

Figure 11 Comparison of load settlement response of $1 \mathrm{~g}$ test and analytical model

At the final load of $1.55 \mathrm{kN}$ the numerical model showed a settlement of $11.1 \mathrm{~mm}$, at the edge and $12.5 \mathrm{~mm}$ at the center as shown in the Figure 12.

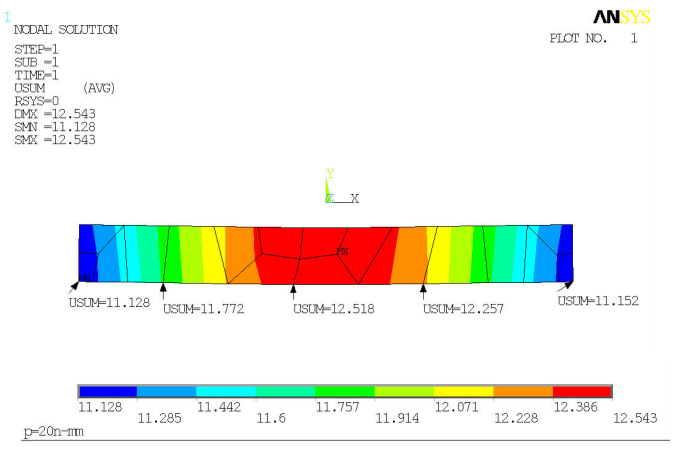

Figure12,Settlement contour

The variation in the settlement between the center and the edge is around $11 \%$. It is seen that the settlement is more at the center of the raft than edge. This difference indicates that the raft-soil system represents the behavior somewhat closer to rigid raft. The Figure 13 presents the stress distribution on the plane strain wall. Although it may not provide the exact shaft stress distribution on the pile, the variation clearly indicates that the major part of the load is transferred by friction as in the case of larger piled raft.

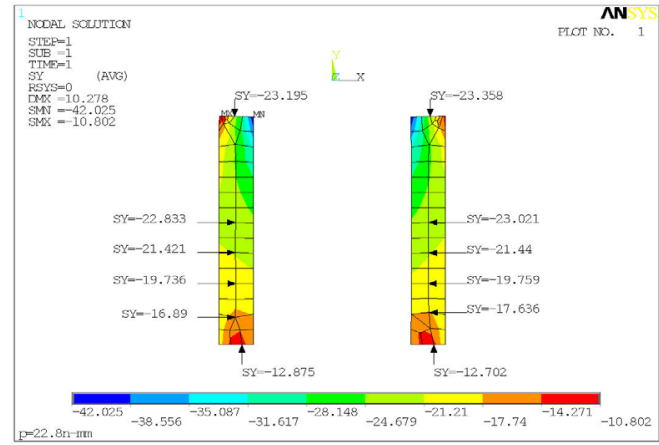

Figure 13- Stress distributions on the plane-strain shaft

\subsubsection{SQUARE FOOTING}

Figure 14 presents the square footing model adopted for the analyses.

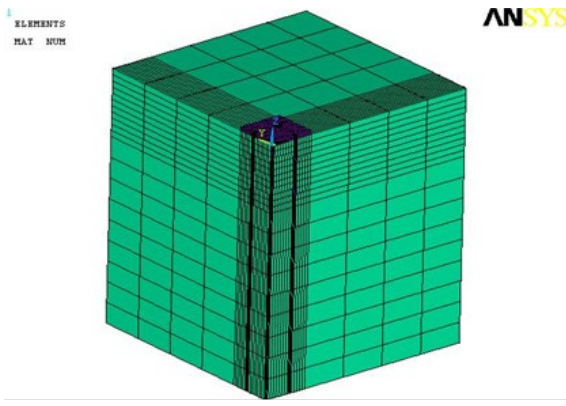

Figure 14Quarter model and finite element mesh adopted for square piled footing in ANSYS nonlinear analysis

In this case three dimensional non linear analyses were carried out .Figure 15 presents the comparison of load settlement response obtained from small scale model tests and the numerical analyses.

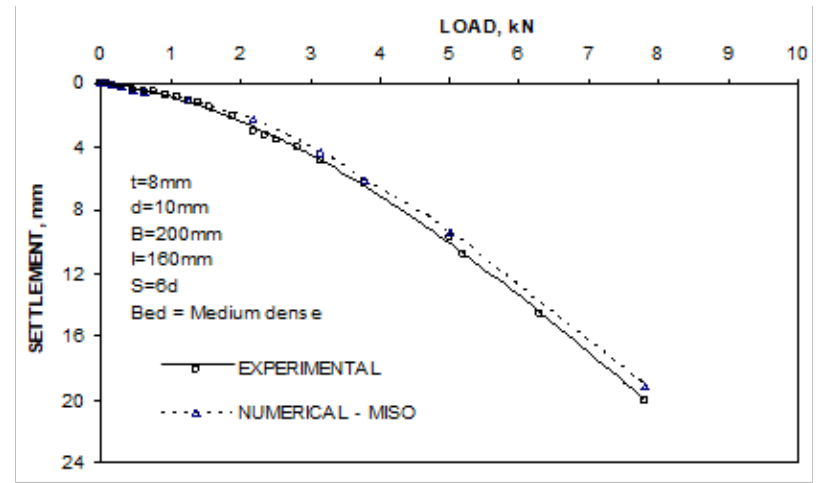

Figure 15 Comparison of load -settlement response between ANSYS and test data for square piled raft with $6 \mathrm{~d}$ pile spacing

The number of piles was kept as 9. The agreement between the two responses is very close although the numerical analysis predicts a stiffer response at higher settlements. .Figure 16 and Figure 17 present the shaft stress distribution at the elastic stage and at the maximum load of $7.7 \mathrm{Kn}$.In either case the rate of reduction is higher at the lower part of the pile than in the top section.

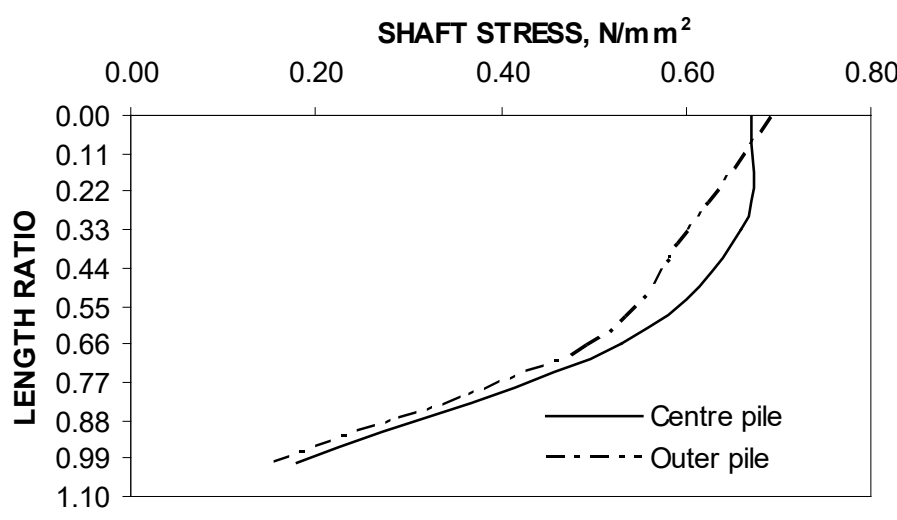

Figure 16 Stress distribution along the pile of square piled raft with 6d-Elastic stage 


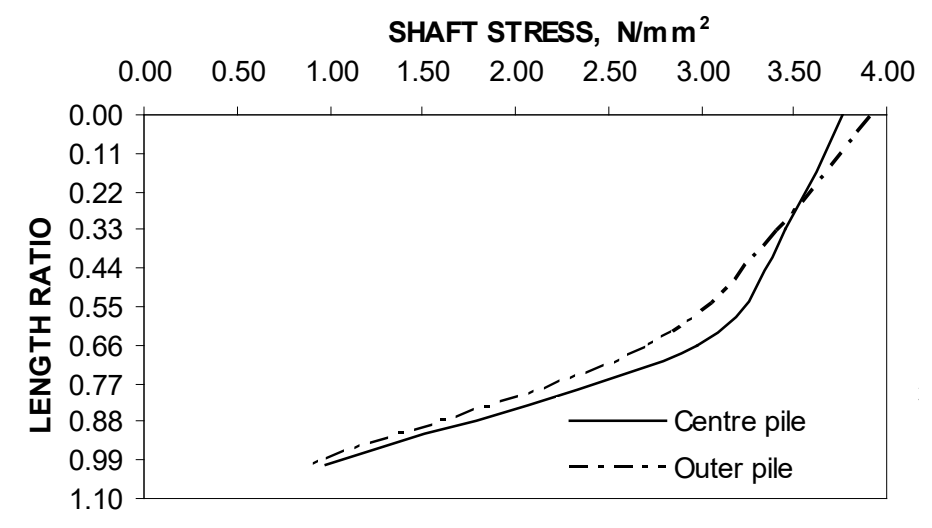

Figure 17 ShaftStress distribution along the pile of square piled raft with $6 \mathrm{~d}$ pile spacing for $7.7 \mathrm{kN}$

In the case of square footing with longer piles beyond 0,7 to 0,81 the shaft stress is very small indicating that the effective length of the pile is around 0.71 to $0, .81$

\section{CONCLUSIONS}

Based on the above study the following conclusions are drawn: It is felt that in this particular type of piled raft the interaction level among the constituent elements appear to be low as shown by the computed interaction factors.

The performance particularly the load sharing response was found to be better when the load was applied as point load between the piles.. However the raft bending moment is likely to increase. In the case of square footing the pile layout gives better confinement of the soil around the pile, as can be seen from the stiffness variation. The central piles take higher load than the outer piles.

The results of analytical study indicate that central un-piled area settles more than the edges where piles have been provided. Therefore a certain amount (perhaps 10\%) differential settlement between the centre and the edges has to be anticipated.

\section{REFERENCES}

Balakumar.V (2008) Experimental Studies of Model Piled Raft on Sand and Field Study of Prototype Behavior. PhD. Thesis, Anna University, Chennai.

Balakumar V, Min Huang Erwin Oh, Mark Bolton and A.S.Balasubramaniam (2013), 'Parametric Study on the Interaction Factor of Piled Raft,' 18th South East Asian Geotechnical And Inaugural AGSSEA Conference 2013, Singapore

Bolton, M.D. and Lau, C.K., (1989), Scale effects in the bearing capacity of granular soils. Pro. of the 12th Int. Conference on Soil Mechanics and Foundation Engineering (pp. 895-898). AA Balkema.

Butterfield R. and Banerjee P.K. (1971), 'The Problem of Pile Group Pile Cap Interaction', Geotechnique 21, No. 2, pp. 135 - 142.

Burland J.B. (1995), Piles as Settlement Reducer, 18th Italian Congress on Soil Mech., Pavia.

Elwakil, A.Z. and Azzam, W.R., (2016). Experimental and numerical study of piled raft system. Alexandria Engineering Journal, 55(1), pp.547-560.

Hongladaromp T , Nan-jimcHEN , Seng-Lip lee - (1973) Load Distribution in Rectangular Footings on Piles-Geotechnical Engineering, vol 4pp 77-90

Katzenbach R., Arslan V. and Moorman ch (2000), Numerical Stimulations of Combined Piled Raft Foundations for the New
High Rise Building, Max in Frankfurt am main, Proc. 2nd Int. Conf. on Soil Structure Interaction in Urban Civil Engineering

Nguyen, D.D.C., Jo, S.B. and Kim, D.S., (2013). Design method of piled-raft foundations under vertical load considering interaction effects. Computers and Geotechnics, 47, pp.16-27.

Oh, W.T. and Vanapalli, S.K., 2013. Scale effect of plate load tests in unsaturated soils. Int. J. of GEOMATE, 4(2), pp.585-594.

Phung Duc Long (1993) Footings With Settlement Reducing Piles in Non Cohesive Soils-Ph.D Thesis, Chalmers Uni. ofTech.,Gothenburg,Sweden

Phung Duc Long (2016)- Settlement analysis for piled raft foundations- $15^{\text {th }}$ Asian Regional conference, 2016, kiushu,Japan

Potts, D. M., and Zdravkovic, L. (2001). Finite element analysis in geotechnical engineering. Application, Thomas Telford, London

Poulos. H.G..(1991)- Analyses of Piled Strip foundation - Computer Methods and advances in Geomechanics ; Beer, Bucker and Carter (eds)-Balkema PP183-191

Poulos, H. G. (2001). "Piled raft foundations: Design and applications."Geotechnique, 512, 95-113.

Poulos H.G. (2008) The Piled Raft Foundation for the Burj Dubai Design \& Performance. IGS - Ferroco Terzaghi, Oration ,2008.

Randolph, M. F. (1994). "Design methods for pile groups and piled rafts." State of the Art Rep., Proc., 13th ICSMFE, Vol. 5, 61-82.

Reul O. and Randolph M.F. (2002), 'Study on the Influence of Finite Element Mesh Refinement on the Calculated Behavior of Piled Raft', Proc. of $8^{\text {th }}$ Int. Symp. Numer. Models. Geomech Rome, pp.259-264.

Weisner.T.J and Brown P.T.- (1975). "The Behaviour of uniformly Loaded Piled Strip Footings" Soils and Foundations, vol 15, No4,Dec 1975

Yamashita.K, Hamada.J, Yamada.T. (2010)

"Field Measurements on Piled Rafts with Grid-Form Deep Mixing Walls on SoftGround",Geotechnical Engg. -SEAGS Vol.42 No 2 June 2011. 